\title{
ASCIÊNCIASSOCIAIS EOBUGDOMILENIO*
}

\section{Elisa P. Reis}

Nesse momento em que chega ao fim meu mandato como presidente da Anpocs, gostaria de aproveitar esta oportunidade para compartilhar com vocês algumas inquietações. Achei que não seria 0 caso de falar sobre minha área particular de interesse ou sobre minha pesquisa em andamento. Seria mais oportuno falar sobre coisas que nos unem, ou nos dividem, mas, de qualquer forma, sobre questões gerais que digam respeito a todos nós.

Gostaria de usar este fórum para compartilhar com vocês, como já disse, algumas dúvidas e inquietações, mas também algumas esperanças em relação às ciências sociais. Inquietações e expectativas que ganham sentido em função do momento histórico atual. Não há dúvida de que há no O cidente uma tendência geral a interpretar o presente como problemático: somos sempre acometidos de um certo presentismo; tendemos a perceber nosso presente como uma crise social sem precedentes. Há um lado muito promissor nisso, pois é em parte da própria necessidade de superar o presente, visto como problemático, que as sociedades formulam

* Conferência proferida no XXII Encontro Anual da Anpocs, Caxambu, 27-30 de outubro de 1998. projetos, buscam se superar. Projetos de intervenção funcionam como aposta em alguma terapia para os males sociais identificados.

Se é verdade que todo presente é vivido como crise, como aporia, não há dúvida de que, em retrospecto, é sempre possível comparar crises e crises. É possível dizer que algumas crises são mais profundas que outras, que algumas mudanças têm conseqüências mais radicais que outras. Historicamente é possível, por exemplo, distinguir entre mudanças revolucionárias e mudanças incrementais. Assim, se falamos de revolução industrial é porque, de fato, mudanças que se observaram na forma de produzir em um dado momento histórico introduziram uma descontinuidade em relação ao passado.

Eu diria que as transformações que a sociedade atravessa ao longo das últimas duas ou três décadas têm algo de descontínuo e radical a ponto de nos permitirem falar de uma nova era. Há uma reconhecida revolução industrial em curso, mas há também uma transformação bastante radical na forma como as sociedades se pensam, ou seja, há também uma revolução político-ideológica em curso. Essas afirmações são triviais, mas se trata de trivialidades cujas conseqüências sociológicas são 
bastantes radicais e que, no entanto, permanecem pouco exploradas.

Há bastante discussão sobre as novas tendências, mas faltam esforços sistemáticos no sentido de se buscar uma visão de conjunto das perspectivas de nossa era. Até mesmo porque parte expressiva das novas tendências é a negação das sínteses e a descrença nas generalizações. Se, por um lado, é verdade que o slogan da globalização está totalmente banalizado, por outro lado é também verdade que a "fragmentação" é percebida como seu corolário entre especialistas. Nesse sentido, observa-se que, no sentido cognitivo e no normativo, a fragmentação é vista como resposta ao movimento globalizador.

Integração e diferenciação crescentes são tendências complementares de longa data identificadas pelas ciências sociais (por exemplo, Durkheim e a divisão social do trabalho; Elias e o processo de ampliação das figurações sociais). Também é muito claro que a história nos sugere que globalização é, em certo sentido, um movimento multissecular. Lembremos, a título de exemplo, a ampliação do comércio mundial, a descoberta do Novo Mundo.

Aqui, contudo, talvez seja o caso de se inverter o dito e dizer: plus c'est la même chose, plus ça change. $O$ movimento globalizador hoje assume características inteiramente novas, características que mexem com a imaginação e com a prática social. Essa novidade coloca desafios para as ciências sociais, desafios que me levam a sugerir alguma analogia com o chamado bug do milênio para a informática.

Que analogia é possível estabelecer? Sabemos muito bem que datas, marcos cronológicos, são convenções sociais mais ou menos ritualizadas. Sabemos também que a idéia do fim do milênio é claramente etnocêntrica, que esse é um entre outros calendários, no caso, aquele que o Ocidente impôs ao resto do mundo em um dos mais precoces sucessos da globalização. No caso da informática, a ameaça do fim do milênio é clara: na virada da meia-noite de 31 de dezembro de 1999 os computadores que estão programados para identificar 0 ano em curso através de dois dígitos identificarão 0 novo ano como 1900, e daí se segue que uma série de rotinas computacionais entrará em colapso e com isso talvez haja severas perdas de informação. Essa é uma ameaça concreta, uma conseqüência previsível de decisões convencionais.

É certo que nas ciências sociais não paira ameaça de catástrofe tão iminente. Por outro lado, também é certo que, no caso da informática, há aposta clara na possibilidade de uma solução técnica em tempo hábil, ao passo que nas ciências sociais a confiança nos próprios recursos científicos anda bastante abalada. Os fabricantes de computadores optaram pelo uso de dois dígitos para a identificação do ano em curso porque havia constrangimentos econômicos sérios que sugeriam a conveniência dessa economia de recursos. De qualquer forma, eles estão confiantes de que, se investirem, haverá uma solução satisfatória para 0 problema que criaram.

E nós, que problema criamos? Há mesmo alguma ameaça pairando sobre o nosso produto, 0 conhecimento social? Creio que, mutatis mutandi, há sim alguma analogia: 0 conhecimento que produzimos está ameaçado de perder relevância. A questão do marco cronológico serve aqui para dramatizar a questão real que diz respeito à magnitude das transformações do presente. As ciências sociais vêm sendo atropeladas pelos fatos.

Nosso desafio, porém, não é inventar solução técnica como aquela que identifique adequadamente 0 ano. Temos problema de informação distinto: temos de nos reciclar rapidamente para reformular nossas questões de investigação. Além disso, creio também que fabricamos um tipo particular de problema análogo ao bug dos computadores: nossa auto-reflexividade parece estar corroendo as próprias bases epistemológicas do que fazemos.

Por exemplo, críticas à ideologia modernizante têm sido feitas com uma certa economia de recursos que hoje ameaça condenar as ciências sociais à futilidade. Por outro lado, a defesa do conservadorismo intelectual faz com que continuemos a formular velhas questões e ignoremos muitas das novas situações e problemas que a sociedade confronta. É verdade que há questões eternas: justiça, igualdade, inclusão versus exclusão... São questões cuja atualidade e relevância são indiscutíveis. Mas, pensar o escopo delas da mesma forma que os sociólogos clássicos 0 fizeram, ou até 
mesmo da maneira como nós fomos treinados no passado, pode ser um anacronismo imperdoável. 0 que é perene é o conteúdo moral subjacente a essas questões. Mas a formulação delas tem de levar em conta seu ambiente histórico concreto.

É a capacidade de interpelar 0 presente que marca a relevância da ciência social. Mesmo refletindo sobre o passado ou especulando sobre 0 futuro, o que a ciência social tem para oferecer de relevante é uma atribuição de sentido ao presente. É precisamente a incapacidade de sensibilizar 0 presente que toma certas críticas estéreis e certas expressões, palavras ou conceitos chavões vazios de conteúdo. As análises sociológicas clássicas continuam clássicas porque decifraram 0 presente de seu tempo e não o nosso.

Ante as grandes transformações sociais da virada do século dezenove para o vinte, Durkheim diagnosticou uma nova forma de solidariedade, de sociabilidade. Weber, por sua vez, identificou um sentido no processo histórico - a racionalização, com suas inúmeras manifestações específicas, tais como a burocratização, a transformação dos fundamentos da modernidade etc. Já mais tarde, às vésperas da Segunda Guerra, Elias concebeu uma rede intrincada de relações que lançava luz sobre os processos históricos de integração e diferenciação. Mesmo Parsons (aparentemente tão descomprometido com a história), ao fazer sua síntese das grandes teorias clássicas, formalizou em variáveis padronizadas uma passagem do tradicional ao moderno que também dava sentido à história. Em todos eles, a preocupação explícita era com a dinâmica social, a mudança social - termo, aliás, que caiu no esquecimento entre cientistas sociais.

Não se pode dizer, propriamente, que os clássicos "descobriram" alguma coisa que existia. 0 que eles souberam foi formular questões relevantes sobre 0 seu momento histórico. Voltando ainda mais atrás, lembremos Marx que, confrontando 0 presente, buscou fundar a ciência que decifrava 0 passado e preparava o futuro. Não podemos cobrar de Marx o fato de ter falhado nas previsões sobre a revolução proletária, pois ele captou com muita adequação a dinâmica da mudança em curso no seu tempo. Mas, no nosso caso, hoje, devemos ao menos estranhar o fato de que não fomos capazes de sequer pressentir a queda dos regimes socialistas ou a implosão da União Soviética. Algo falhou seriamente em nossa capacidade de análise nesse caso. Esse fracasso deveria nos tornar mais humildes por um lado, e, por outro, mais atentos e sensíveis às implicações das transformações em curso.

Parece-me um equívoco uma certa tendência a interpretar a queda do Segundo Mundo como o triunfo inconteste do Primeiro. Se esse é o cenário pragmático de curto prazo no tabuleiro da geopolítica, não há nada que nos permita inferir daí um triunfo final do velho capitalismo. A disputa momentânea entre duas formas de produzir foi superada, mas a história continua. E não vejo um programa de pesquisa consistente voltado para 0 exame seja das tendências do capitalismo, seja da evolução do problema do desemprego, ou mesmo das conseqüências de tais mudanças para a formação de cientistas sociais.

Se o Estado foi, tradicionalmente, um grande empregador de cientistas sociais, decerto seu encolhimento tem já um impacto significativo sobre nosso mercado de trabalho. Isso já começa a ser sentido nos países onde o welfare é mais desenvolvido. Por outro lado, lá e cá parece-me que, com a privatização da oferta de bens e serviços tradicionalmente oferecidos pelo setor público, está surgindo a necessidade de funções de supervisão e controle novas. Isto é, será preciso treinar rapidamente profissionais para o exercício de funções de controle da oferta privada de serviços públicos como estradas, telefonia, saneamento, água etc.

Mesmo em uma área de atuação relativamente nova, que os cientistas sociais têm conseguido ocupar com bastante sucesso (em uma mostra de notável adaptabilidade), parece-me que estamos muitas vezes mal preparados para responder às demandas de conhecimento e confundimos nosso fervor ético-religioso com eficiência. Refiro-me à atuação em agências não-governamentais e em organizações filantrópicas em geral. Também nessa área de atuação somos com freqüência atropelados pelos fatos. Continuamos, em certo sentido, presos à retórica política de décadas anteriores e não nos damos conta de que o mundo que nos circunda se tornou infinitamente mais complexo. 
O conhecimento que produzimos se torna obsoleto com rapidez crescente. Não porque novos conhecimentos e teorias nos atropelem, mas porque novas realidades nos surpreendem enquanto nossos modelos e recursos metodológicos se mostram com freqüência anêmicos e incapazes de gerar programas de pesquisas progressivos.

Onde estaria a saída? Como identificar nossos pontos fortes? Que sinais animadores podemos localizar no cenário econômico, social e intelectual? Sabemos, em termos puramente quantitativos, que apesar do fato de que a desigualdade está crescendo dentre e entre nações, existiriam hoje condições para se eliminar a miséria material no mundo. Mas sabemos também que não dispomos de condições políticas e mesmo técnicas para resolver 0 problema. Os cientistas sociais não conseguem equacionar o quebra-cabeça da política social: como sensibilizar os que são passíveis de tributação, como fazer chegar os recursos aos mais necessitados, como minimizar o desperdício, a grande e a pequena corrupção? Quais são as externalidades negativas da pobreza hoje? Como os não-pobres percebem tais externalidades? Que processos afetam positiva e negativamente a solidariedade entre grupos, classes ou nações? Tais questões urgentes têm sido amplamente negligenciadas.

Claro que esses problemas não são novos. São parte de nossa tradição de pesquisa. Mas não temos sabido muito bem como enquadrá-los na moldura do presente. Como entender, por exemplo, a problemática dos direitos sociais em um contexto histórico no qual as bases tradicionais de legitimação da cidadania estão abaladas? Por exemplo, até mesmo direitos sociais já sacralizados nas constituições mais duradouras do Primeiro Mundo foram revistos nos anos recentes. Entre nós, as propostas recentes de revisão de direitos trabalhistas indicam claramente uma fragilidade sem precedentes no mercado de trabalho formal.

Quais foram as grandes questões deste século para os cientistas sociais? De maneira geral, creio que concordamos em listar entre elas a industrialização, a urbanização, a construção do Estado nacional, a mobilização social, a expansão da cidadania. E é também inegável que algumas delas, pelo menos da forma como estavam postas, não formulam mais questões de pesquisa relevantes no contexto histórico atual.

Essa é uma ambigüidade iniludível nas ciências sociais: nossas questões são eternas vistas sob certo prisma, mas por outro elas são completamente volúveis, mudam com rapidez espantosa. Quantos de nós já demos cursos ou fizemos pesquisas sobre temas cuja formulação seria incapaz de atrair alunos ou sensibilizar agências de financiamento? Disjuntivas que colocávamos do tipo "reforma ou revolução", "crescimento ou distribuição", seriam consideradas hoje totalmente deslocadas. Isso nada tem a ver com sua pertinência ou não no passado. Mesmo que as disjuntivas se tenham revelado falsas, a verdade é que tais formulações dilemáticas cumpriram papel importante não apenas na mobilização de recursos políticos, mas também na formação de comunidades de pesquisa.

Nesse sentido, mais do que nunca, a idéia segundo a qual as ciências sociais são etemamente jovens torna-se relevante. Sem perder 0 apelo moral que a justificava, a ciência social do presente vê-se compelida a reformular suas questões. Sabemos que os dilemas sobre os quais nos debruçamos em décadas passadas desapareceram, muitas vezes sem que tivéssemos chegado a alguma conclusão ou alguma proposta de solução dos mesmos. Nossos dilemas eram supérfluos ou desprovidos de sentido? Certamente que não. Discuti-los foi de importância crucial para nossas sociedades. Mas não podemos nos eximir de formular novas questões, sob pena de cairmos, aí sim, na falta de sentido.

Que não seja mais aceitável fundamentar 0 discurso sociológico exclusivamente em termos de classes, do projeto do Estado nacional e de uma ideologia desenvolvimentista, muda bastante nossa prática profissional. Que valores e crenças legitimam a prática acadêmica ou intelectual hoje? Como se enunciam as questões morais de nosso tempo? Que questões sociais estão na ordem do dia? Certamente há uma agenda de questões universalmente válidas. Temas como violência, o crescimento da economia submersa, o desconcertante crescimento da exclusão social, mesmo nos países mais desenvolvidos, mobilizam atenções em todo 0 
planeta. Simultaneamente, há conceitos em alta por toda parte que sinalizam uma convergência das prioridades dos cientistas sociais: cidadania, democracia, sociedade civil, solidariedade, comunitarismo, identidades sociais, ao lado de globalização e pós-modemidade, estão entre os conceitos mais recorrentes, como atestam os índices remissivos dos livros publicados nesta década.

Não há dúvida de que as questões da ciência social seguem sendo cruciais. Mais ainda, há bastante empenho na identificação das novas questões. Contudo, parece que grande parte do esforço intelectual empreendido tem-se limitado a chamar a atenção para a novidade delas, sem um esforço de teorizar ou de entender as implicações sociais de tais novas questões. Quais são, por exemplo, as implicações das novas formas de produzir para a estrutura familiar, para a mobilidade social, para a manutenção da ordem, para as políticas sociais etc.? Sabe-se pouco e especula-se pouco sobre tais questões. Há muito empenho em salientar o que mudou, e muito menos em investigar como tais mudanças afetam a vida da sociedade como um todo.

Será que não nos sentimos mais em condições de pensar a sociedade como um todo? Será que, seguindo o processo de fragmentação social em curso, vamos caminhar no sentido de nos especializarmos sempre na consideração de processos ou interesses particulares? Isso seria uma reversão da proposta original da Sociologia, que sempre pensou a exclusão como fenômeno persistente mas continuamente problemático.

As ciências sociais surgiram como parte do projeto iluminista. Surgiram com base na crença de que é possível progredir, melhorar as condições de vida de toda a sociedade. Todas as proposições do Iluminismo são de natureza progressista, universalizante, inclusiva. Nesse sentido, havia uma ideologia em expansão que dava sentido à prática da ciência em geral e da social em particular: afirmação crescente da liberdade, da afluência, do bemestar, da convivência pacífica, da democracia.

Claro que esta ideologia comportava muitos matizes e variações, versões mais ou menos otimistas, estratégias graduais ou revolucionárias, liberais ou despóticas. De uma maneira geral, acreditava-se na capacidade de intervenção humana para a melhoria das condições materiais e ideais de vida. No seio desse movimento - no qual a modernização era um processo, mas também um projeto diversos argumentos ganharam força: igualdade crescente, cidadania, nação, industrialismo etc. Tais argumentos forneceram 0 arsenal de que se valeram as ciências sociais. Ao longo do tempo essas crenças e idéias tornaram-se mais e mais disseminadas, até se tornarem uma espécie de lugar-comum ou uma "naturalidade". Nesse contexto surgiram projetos políticos e intelectuais de transformação social.

No alvorecer da era moderna, as diferenciações que a sociedade estabeleceu entre 0 mercado e o Estado, a filosofia e a ciência, tiveram conseqüências intelectuais e materiais definitivas na organização social. É verdade que a expansão vertiginosa das comunicações na virada dos séculos dezoito e dezenove transformou de forma revolucionária a vida da sociedade e tornou possível muitas das conquistas da era moderna (alfabetização, diálogo, opinião pública, democracia etc.). Mas, não será verdade também que vivemos uma nova era de transformações, que 0 incremento novamente vertiginoso das comunicações traz novas potencialidades emancipadoras?

Nós que fomos treinados nessa segunda metade do século vinte, acostumamo-nos a pensar que a sociedade natural é a que coincide com o Estadonação, que a maneira natural de se inserir na sociedade é a partir da produção material, que a sociedade tem duas esferas analíticas básicas, 0 Estado e 0 mercado. Hoje isso está mudando na percepção social: tendemos a ver 0 Estado e 0 mercado como esferas "fora" da sociedade civil, que passa a ser vista como uma terceira esfera. Não se trata de questionar a pertinência dessa percepção: se a sociedade se pensa dessa maneira tripartite, tal percepção se tornou sem dúvida pertinente.

Em certo sentido, a situação parece madura para o surgimento de novos tipos de mecanismos protetores do tecido social. Parece que estamos vivendo uma nova Grande Transformação, com todas as tensões e dificuldades que isso traz. A própria idéia de separar a sociedade como esfera analítica distinta do mercado (e também do Estado) 
pode ser percebida como um esforço ideológicocultural de preservação do social. Ante a ameaça desagregadora do mercado, triunfante no nível ideológico, a postulação de uma esfera analítica da solidariedade parece uma volta à dicotomia comunidade/ sociedade, mas, claramente, ela incorpora dimensões e questões que não estavam presentes um século atrás.

Parafraseando Polanyi, pode-se dizer que os movimentos virtuais do capital financeiro correspondem, de certa forma, ao que foi a transformação do trabalho em mercadoria, que tanta atenção mereceu de Marx. Terra e trabalho foram transformados em capital, embora fossem, na verdade, natureza e atividade humana. Temos agora uma nova situação de artificialidade: a mera intenção de comprar e vender é suficiente para substituir o dinheiro. A artificialidade da moeda virtual parece colocar em sério risco a vida da sociedade. A instabilidade do mercado financeiro tornou-se, no momento, a maior e mais ampla ameaça à vida das diferentes sociedades. Mesmo as sociedades relativamente estáveis da Europa, que têm conseguido índices de crescimento estáveis, taxas relativamente baixas de corrupção e graus de desigualdade relativamente pequenos, vêem-se ameaçadas pelo furacão que assola os mercados de ações.

Como exemplo claro da interdependência global, olhemos por um instante para a Europa Ocidental: a Comunidade Européia projeta um crescimento de aproximadamente $2 \%$ para 0 próximo ano, sugerindo que, no geral, há bastante estabilidade na economia, mas todos analistas insistem na ressalva de que pode haver um cataclismo social e econômico se a crise financeira, totalmente externa à Comunidade, se alastrar. Apesar do fato de que nesse pedaço do mundo há menos desigualdade, as finanças públicas estão relativamente equilibradas, há menos corrupção e a burocracia é mais eficiente, a Europa não estará imune aos efeitos da crise financeira.

Claro que se pode dizer que, invocando Polanyi e a autoproteção da sociedade, estou usando um discurso anacrônico para falar dos novos problemas que nos afligem e que, desse jeito, estou precisamente comprando o risco do bug do milênio. Claro que se pode dizer também que muitas das aspirações ou previsões do Iluminismo foram frustradas, que o seu otimismo universalizante não se cumpriu. É verdade, por exemplo, que o progresso convive com e gera mesmo novas formas de exclusão.

Contudo, ao invés de nos comprazermos na denúncia, na autopiedade diante dos fracassos das ciências sociais, por que não nos dedicarmos a buscar onde é que estão os pontos vulneráveis, onde é que é preciso romper com as pressuposições correntes da análise e da política social? Por exemplo, por que não somos capazes de acabar com a pobreza quando há recursos para isso? Creio que essa é a maneira de livrar a ciência social do bug. Se nos limitarmos a apontar em prosa e verso os fracassos das grandes narrativas, das especializações, dos pragmatismos etc., talvez tenhamos sucesso expressivo; talvez logremos mesmo sermos artífices de novas disciplinas. Mas estaremos, creio, abrindo mão da herança das ciências sociais. Estaremos abrindo mão do legado de Marx, de Weber e de tantos outros.

O Pós-Modernismo pode ser pensado como uma reação ao Iluminismo. Essa reação tanto poderá ter conotações progressistas como reacionárias. Como uma crítica à racionalidade, ao individualismo, à ideologia do progresso, ela própria pode assumir características emancipadoras ou, ao contrário, se transformar em uma prática niilista e conformista. Ou seja, a crítica pós-modernista tanto pode ser vista como 0 antídoto quanto como 0 próprio bug das ciências sociais. Naturalmente, a opção progressista implica a radicalização da modernização. Em outras palavras, estou sugerindo que a ciência social não tem salvação fora do projeto racionalizante.

Enquanto as demais ciências seguem o caminho progressivo e levam à frente 0 ideal modernizante, as ciências sociais parecem mergulhar em uma crise de autoconfiança. Os ideais modemizantes tornaram-se alvo de crítica feroz e, sem eles, os próprios críticos não sabem como legitimar sua inserção como cientistas. Essa legitimação parece se dar muito mais mediante uma adesão explícita a um credo particular, de natureza política, religiosa ou hedonístico. Claro que há exceções, mas esse não é o contexto para discorrer sobre elas. 
O chamado fim das grandes narrativas que, na verdade, se torna inteligível através de alguma nova grande narrativa - deixa as ciências sociais sem especificidade. A saída do reencantamento do mundo, embora plenamente legítima como opção pessoal, não pode, infelizmente, salvar a ciência social. Parece que, se quisermos preservar a especificidade do conhecimento científico diante de outras formas de conhecimento, será impossível abrir mão do recurso à razão, da busca da generalização e da aposta na universalização. É nesse sentido que gostaria de mencionar um dos conceitos da ciência social que me parecem, hoje, mais sugestivos da promessa de radicalização do projeto modernizante e emancipacionista das ciências sociais. Refiro-me ao conceito de cidadania.

Esse conceito hoje simboliza bem 0 "progressismo", o movimento inclusivo e universalizante que historicamente caracterizou as ciências sociais. Digo hoje porque em outras conjunturas "cidadania" não tinha o mesmo élan progressista e muitos até a identificavam como mistificação política para encobrir a verdadeira dominação. Hoje, no contexto de revalorização da democracia política, a noção de cidadania voltou a ocupar um lugar central dentro das ciências sociais.

Claro que a afirmação da cidadania como projeto tem hoje conotações novas, bastante distintas das que teve no passado. Assim, é importante observar que, hoje, a idéia de afirmação da cidadania se descola crescentemente do projeto de afirmação do Estado nacional. No passado, expandir a cidadania era simultaneamente fortalecer a nação. À medida que o Estado nacional se consolidava, universalizava-se a condição cidadã em um dado espaço geopolítico.

Hoje, demandas por cidadania expressam muito mais claramente a tensão entre demandas por igualdade e por diferença, ou melhor, evidenciam os dilemas da inclusão versus exclusão que a mística do Estado nacional tendia a ocultar. Se, durante décadas, assistimos o avanço da cidadania evidenciar a igualdade, incluindo no consumo do acervo comum de direitos camadas cada vez mais amplas da sociedade, hoje ele explicita também, com vigor crescente, demandas pelo direito à diferença.
Essa questão é cheia de tensões, dilemas e ambigüidades. Talvez aqui esteja 0 maior dos bugs que nos ameaçam hoje: como reconciliar igualdade e diferença, dilema que talvez não seja muito diferente do velho desafio tocquevilliano de equacionar igualdade e liberdade.

Não se espera dos cientistas sociais a clarividência, ou melhor, a alquimia de fundir logicamente noções dilemáticas. Contudo, é legítimo esperar que eles logrem formular o velho dilema de maneiras novas e originais, de forma a não retroceder no tempo - ameaça idêntica a que enfrentam os computadores na virada do milênio. Esperemos também que a novidade do direito à diferença não nos tente a abrir mão da velha luta pelo direito à igualdade. Esse é um bug, uma ameaça, melhor dizendo, que se insinua perigosamente no encolhimento do welfare, no recrudescimento da exclusão social e, ouso dizer, no interior das ciências sociais - no descuido das questões gerais, no abandono das generalizações que, logicamente, não excluem o estudo de casos e causas particulares mas não podem, de qualquer forma, se confundir inteiramente com esses últimos. 